\title{
Simultaneous Heat and Mass Transfer in Inclined Channel with Asymmetrical Conditions
}

\author{
O. Oulaid ${ }^{1,2}$, B. Benhamou ${ }^{1 \dagger}$ and N. Galanis ${ }^{2}$ \\ ${ }^{1}$ LMFE (CNRST - URAC 27), Physics Department, Faculty of Sciences Semlalia, Cadi Ayyad University Marrakech, \\ Morocco \\ ${ }^{2}$ THERMAUS, Département de génie mécanique, Université de Sherbrooke, Sherbrooke, J1K 2R1, Québec, Canada
}

†Corresponding Author Email: BBenhamou@ucam.ac.ma

(Received June 21, 2010; accepted October 10, 2010)

\begin{abstract}
The present work is a numerical study of simultaneous heat and mass transfer with phase change in an inclined channel formed by two parallel plates. The lower one is covered by a thin liquid water film and the upper one is considered impermeable. The plates are maintained at a constant temperature. The liquid film is assumed to be extremely thin and its temperature is uniform and equal to that of the wall. Thermo-physical properties are considered constant and the Boussinesq assumption is adopted. Results show that the effects of the buoyancy forces on the hydrodynamic, thermal and mass fraction fields are important. These effects depend on the channel inclination and may result on flow reversal when the channel approaches the vertical position. This phenomenon is addressed and a flow reversal chart, as well as the corresponding correlations, for different channel inclinations is given. These correlations give the values of Grashof numbers, which induce flow reversal for a given Reynolds number and inclination angle.
\end{abstract}

Keywords: Mixed convection, Phase change, Flow reversal chart.

\section{NOMENCLATURE}

b half width of the channel [m]

C dimensionless mass fraction,

$=\left(\omega-\omega_{\text {in }}\right) /\left(\omega_{\mathrm{w}}-\omega_{\text {in }}\right)$

D mass diffusion coefficient $\left[\mathrm{m}^{2} \mathrm{~s}\right]$

$\mathrm{D}_{\mathrm{h}} \quad$ hydraulic diameter, $=4 \mathrm{~b}[\mathrm{~m}]$

$f \quad$ friction factor

g gravitational acceleration $\left[\mathrm{m} \mathrm{s}^{-2}\right]$

$\mathrm{Gr}_{\mathrm{M}}$ solutal Grashof number,

$=\mathrm{g} \beta_{\mathrm{M}} \mathrm{D}_{\mathrm{h}}{ }^{3}\left(\omega_{\mathrm{w}}-\omega_{\mathrm{in}}\right) / v^{2}$

$\mathrm{Gr}_{\mathrm{T}}$ thermal Grashof number,

$$
=\mathrm{g} \beta_{\mathrm{T}} \mathrm{D}_{\mathrm{h}}^{3}\left(\mathrm{~T}_{\mathrm{w}}-\mathrm{T}_{\text {in }}\right) / v^{2}
$$

h local heat transfer coefficient $\left[\mathrm{W} \mathrm{m}^{-2} \mathrm{~K}^{-1}\right]$

$\mathrm{h}_{\mathrm{m}} \quad$ local mass transfer coefficient $\left[\mathrm{m} \mathrm{s}^{-1}\right]$

$\mathrm{h}_{\mathrm{fg}} \quad$ latent heat of vaporization $\left[\mathrm{J} \mathrm{kg}^{-1}\right]$

$\mathrm{k}$ thermal conductivity $\left[\mathrm{W} \mathrm{m}^{-1} \mathrm{~K}^{-1}\right]$

$\mathrm{L}$ channel height [m]

$\mathrm{M}_{\mathrm{a}} \quad$ molecular mass of air $[\mathrm{kg} / \mathrm{kmol}]$

$\mathrm{M}_{\mathrm{v}} \quad$ molecular mass of water vapor $[\mathrm{kg} / \mathrm{kmol}]$

$\mathrm{Nu}_{\mathrm{S}}$ sensible heat transfer local Nusselt number

$\mathrm{Nu}_{\mathrm{L}}$ latent heat transfer local Nusselt number.

$\mathrm{P}_{\mathrm{m}} \quad$ dimensionless modified pressure,

$=\left(p+\rho_{\text {in }} g(x \sin \varphi+y \cos \varphi)\right) / \rho_{\text {in }} \cdot u_{\text {in }}{ }^{2}$

Pr Prandtl number, $=v / \alpha$

$\rho \quad$ density $\left[\mathrm{kg} \mathrm{m}^{-3}\right]$

$\omega \quad$ mass fraction [ $\mathrm{kg}$ of vapor/ $\mathrm{kg}$ of mixture]

Subscripts

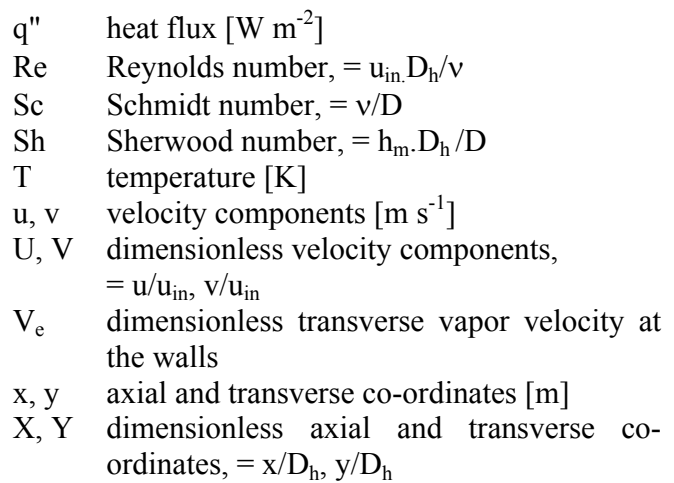

\section{Greek symbols}

$\alpha \quad$ thermal diffusivity $\left[\mathrm{m}^{2} \mathrm{~s}\right]$

$\beta_{\mathrm{T}} \quad$ coefficient of thermal expansion, $=1 / \mathrm{T}_{\text {in }}\left[\mathrm{K}^{-1}\right]$

$\beta_{\mathrm{M}} \quad$ coefficient of mass fraction expansion, $=\mathrm{M}_{\mathrm{a}} / \mathrm{M}_{\mathrm{v}}-1$

$\gamma \quad$ aspect ratio of the channel, $=2 \mathrm{~b} / \mathrm{L}$

$\theta$ dimensionless temperature, $=\left(\mathrm{T}-\mathrm{T}_{\text {in }}\right) /\left(\mathrm{T}_{\mathrm{w}}-\mathrm{T}_{\text {in }}\right)$

$v \quad$ kinematic viscosity $\left[\mathrm{m}^{2} \mathrm{~s}^{-1}\right]$

$\phi \quad$ relative humidity $(\%)$ 
L relative to latent heat transfer

$\mathrm{m}$ mean value

\section{INTRODUCTION}

The phenomena of coupled heat and mass transfer have been extensively studied in the literature and the majority of the published works focus on horizontal and vertical configurations. Among the recent studies Laaroussi et al. (2009) conducted a numerical study of laminar mixed convection in a vertical parallel-plate channel with evaporation of thin liquid films wetting the walls. The plates were maintained at a constant temperature and the liquid film thickness was assumed to be negligible. The airflow is directed downward and the film was either liquid water or hexane. The authors compared the results obtained with constant properties (Boussinesq model) with those calculated by considering variable density.

Ait Hammou et al. (2004) have examined numerically the effects of simultaneous heat and mass transfer on downward laminar flow of humid air in an isothermal vertical channel with wetted walls. They affirmed that, depending on the inlet conditions of the humid air, mass transfer may result in evaporation or condensation. On the other hand, it was demonstrated that thermal and solutal buoyancy forces have significant effects on flow characteristics. In all cases analyzed in this study, the authors have not detected flow reversal. Combined buoyancy effects of thermal and mass diffusion on laminar mixed convection in a vertical isothermal channel were also studied by Oulaid et al. (2010a). The results show that buoyancy forces decelerate the flow near the channel walls and cause flow reversal.

Heat and mass transfer mixed convection in inclined geometries has not been extensively studied as in vertical and horizontal configurations. Among the few studies addressing inclined configurations we mention that of Said et al. (2005), who investigated numerically turbulent natural heat convection between inclined isothermal plates. Their results show that the average Nusselt number is reduced as the inclination angle increases and that the overall average Nusselt number at different inclination angles can be presented by a single correlation. The problem of heat transfer enhancement through film evaporation in inclined square ducts mixed convection was studied numerically by Jang et al. (2005). Their results show that the friction factor as well as heat and mass transfers are seriously affected by the inclination angle. Moreover, heat transfer rate can be enhanced to be 10 times of that without film evaporation, especially for a system with a lower temperature.

Rheault and Bilgen (1993) studied numerically steady laminar mixed heat convection in vertical and inclined parallel-plate channels with asymmetric isothermal boundary conditions. The authors show that the solution of the problem with flow reversal can be achieved in the range of Peclet numbers from 10 to 150 , where the effect of axial diffusion becomes critical. Thus their results show that the flow reversal near the colder wall at the inlet

relative to sensible heat transfer

at the wall

and/or the center of the channel becomes more pronounced when the Richardson number $\mathrm{Gr} / \mathrm{Re}^{2}$ increases.

A two-phase modeling of laminar film condensation from vapor-gas mixtures in inclined parallel-plate channels was presented by Siow et al. (2007). The upper plate is insulated and impermeable while the bottom one is wetted by a liquid film and maintained isothermal. The model uses a finite-control-volume method to solve the two-phase boundary-layer equations. The authors' results show that, increasing the angle of inclination produces thinner, faster moving films. Increasing Reynolds number always produced thinner films and higher Nusselt number. An exact analytical solution for the liquid and mixture axial velocity profiles under end of condensation conditions is also presented and compared with the numerical results.

In a previous work (Oulaid et al. 2010a) we studied combined buoyancy effects of thermal and mass diffusion on laminar mixed convection in a vertical isothermal channel. The results show that buoyancy forces decelerate the flow near the channel walls and cause flow reversal. More recently (Oulaid et al. 2010b) we investigated flow reversal in combined heat and mass transfer laminar mixed convection with phase change in a vertical channel. The conditions for the existence of flow reversal are presented in charts and analytical expressions specifying the critical thermal Grashof number as a function of the Reynolds number for different values of the solutal Grashof number and different aspect ratios of the channel.

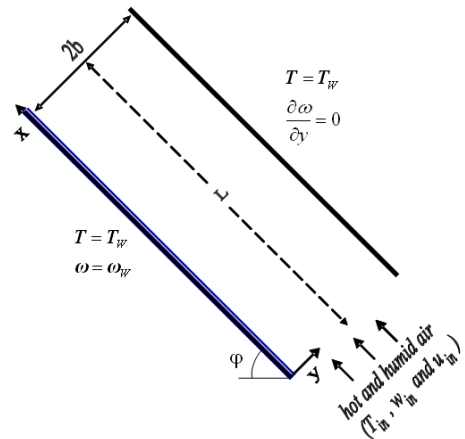

Fig. 1. Schematic representation of the physical system

The principal aim of the present investigation is to study the influence of the channel inclination on the hydrodynamic, thermal and mass fraction fields, as well as to present criteria for the occurrence of the phenomenon of flow reversal.

\section{DisCRIPTION AND MODELING OF THE Problem}

We consider a $2 b$ spaced, parallel-plate inclined channel (Fig. 1). These plates are subject to a uniform temperature $T_{w}$ and the lower one is wetted by a thin 
liquid water film while the upper plate is impermeable. The air enters with a uniform velocity $\mathrm{u}_{\mathrm{in}}$, and constants temperature $T_{\text {in }}$ and mass fraction $\omega_{i n}$. The upward airflow is considered laminar and steady. We consider that radiation, the heat transfer by inter-diffusion of species, viscous dissipation and the work of the compressive forces, as well as the Dufour and Soret effects, as negligible (Gebhart and Pera, 1971). Physical properties are supposed to be constant except for the density in the body forces which is considered as a linear function of temperature and mass fraction (Boussinesq approximation)

$$
\rho=\rho_{\text {in }}\left[1-\beta_{T}\left(T-T_{\text {in }}\right)-\beta_{M}\left(\omega-\omega_{\text {in }}\right)\right]
$$

This assumption was proposed by Boussinesq (1903) and it was extensively used in the literature (Yan and Soong 1993, Rheault and Bilgen 1993, Jang et al. 2005, Said et al. 2005, Laaroussi et al. 2009). The validity of the later was investigated by Gray and Giorgini (1976). Authors present a new method for obtaining approximate equations for natural convection flows. Their results showed that this method allows the specification of the conditions under which the traditional Boussinesq approximation applies to a given Newtonian fluid and gases. These conditions are prevalent in the present study.

The liquid film is assumed to be extremely thin so that they can be treated as a boundary condition. This simplification allows us to handle only the conservation equations in the gas flow. The liquid film is therefore assumed to be at the wall temperature. Yan and Soong (1993) have stated that this assumption is valid for small liquid mass flow rates. Under the above assumptions, the dimensionless governing equations of the problem can be written

Continuity equation

$$
\frac{\partial \mathrm{U}}{\partial \mathrm{X}}+\frac{\partial \mathrm{V}}{\partial \mathrm{Y}}=0
$$

Streamwise momentum equation

$$
\begin{aligned}
\left(\mathrm{U} \frac{\partial \mathrm{U}}{\partial \mathrm{X}}+\mathrm{V} \frac{\partial \mathrm{U}}{\partial \mathrm{Y}}\right)= & -\frac{\partial \mathrm{P}_{\mathrm{m}}}{\partial \mathrm{X}}+\frac{1}{\operatorname{Re}}\left(\frac{\partial^{2} \mathrm{U}}{\partial \mathrm{X}^{2}}+\frac{\partial^{2} \mathrm{U}}{\partial \mathrm{Y}^{2}}\right) \\
& +\frac{\sin \varphi}{\operatorname{Re}^{2}}\left(\mathrm{Gr}_{\mathrm{T}} \theta+\mathrm{Gr}_{\mathrm{M}} \mathrm{C}\right)
\end{aligned}
$$

Spanwise momentum equation

$$
\begin{aligned}
\left(\mathrm{U} \frac{\partial \mathrm{V}}{\partial \mathrm{X}}+\mathrm{V} \frac{\partial \mathrm{V}}{\partial \mathrm{Y}}\right)= & -\frac{\partial \mathrm{P}_{\mathrm{m}}}{\partial \mathrm{Y}}+\frac{1}{\operatorname{Re}}\left(\frac{\partial^{2} \mathrm{~V}}{\partial \mathrm{X}^{2}}+\frac{\partial^{2} \mathrm{~V}}{\partial \mathrm{Y}^{2}}\right) \\
& +\frac{\cos \varphi}{\operatorname{Re}^{2}}\left(\mathrm{Gr}_{\mathrm{T}} \theta+\mathrm{Gr}_{\mathrm{M}} \mathrm{C}\right)
\end{aligned}
$$

Energy equation

$$
\left(\mathrm{U} \frac{\partial \theta}{\partial \mathrm{X}}+\mathrm{V} \frac{\partial \theta}{\partial \mathrm{Y}}\right)=\frac{1}{\operatorname{Pr} \operatorname{Re}}\left(\frac{\partial^{2} \theta}{\partial \mathrm{X}^{2}}+\frac{\partial^{2} \theta}{\partial \mathrm{Y}^{2}}\right)
$$

Species conservation equation

$$
\left(\mathrm{U} \frac{\partial C}{\partial \mathrm{X}}+\mathrm{V} \frac{\partial C}{\partial \mathrm{Y}}\right)=\frac{1}{\operatorname{Sc} \operatorname{Re}}\left(\frac{\partial^{2} C}{\partial \mathrm{X}^{2}}+\frac{\partial^{2} C}{\partial \mathrm{Y}^{2}}\right)
$$

The boundary conditions for the problem under consideration are

- At the inlet $(\mathrm{X}=0)$ :

$\mathrm{U}=1$ and $\mathrm{V}=\mathrm{C}=\theta=0$

- At the outlet $\left(\mathrm{X}=\mathrm{L} / \mathrm{D}_{\mathrm{h}}\right)$ :

$\frac{\partial U}{\partial X}=\frac{\partial V}{\partial X}=\frac{\partial \theta}{\partial X}=\frac{\partial C}{\partial X}=0$

- At the lower plate $(\mathrm{Y}=0)$ :

$\mathrm{U}=0, \mathrm{~V}=\mathrm{V}_{\mathrm{e}}$ and $\mathrm{C}=\theta=1$

- At the upper plate $(\mathrm{Y}=0.5)$ :

$\mathrm{U}=0, \mathrm{~V}=0, \theta=1$ and $\frac{\partial C}{\partial X}=0$

where the non-dimensional transverse velocity at the interface is (Burmeister 1993)

$$
V_{e}=\frac{-1}{\operatorname{ReSc}} \frac{\left(\omega_{w}-\omega_{i n}\right)}{\left(1-\omega_{w}\right)}\left(\frac{\partial C}{\partial Y}\right)_{Y=0}
$$

By assuming that air-vapor mixture is an ideal gas mixture, the mass fraction at the lower wall $\omega_{\mathrm{w}}$ which corresponds to the saturation conditions at $\mathrm{T}_{\mathrm{w}}$, is calculated by the following expression (Yan and Soong 1995)

$$
\omega=\frac{M_{v} p_{\text {sat }}(T)}{M_{a}\left(p-p_{\text {sat }}(T)\right)+M_{v} p_{\text {sat }}(T)}
$$

The Nusselt number is

$$
N u_{T}=\frac{h D_{h}}{k}=\frac{q_{T}^{\prime \prime} D_{h}}{k\left(T_{w}-T_{m}\right)}=N u_{S}+N u_{L}
$$

Where

$$
\begin{aligned}
& N u_{S}=-\left.\frac{1}{1-\theta_{m}} \frac{\partial \theta}{\partial Y}\right|_{Y=0} \\
& \mathrm{Nu}_{\mathrm{L}}=-\left.\frac{\mathrm{S}}{1-\theta_{\mathrm{m}}} \frac{\partial \mathrm{C}}{\partial \mathrm{Y}}\right|_{Y=0}
\end{aligned}
$$

and

$$
S=\frac{\rho D h_{f g}}{k} \frac{\left(\omega_{w}-\omega_{i n}\right)}{\left(1-\omega_{w}\right)} \frac{1}{\left(T_{w}-T_{i n}\right)}
$$

$S$ represents the relative importance of energy transport through species diffusion to that through thermal diffusion.

The Sherwood number characterizes mass transfer at the interface Oulaid et al. (2010b)

$$
S h=\frac{h_{m} D_{h}}{D}=-\left.\frac{1}{1-C_{m}} \frac{\partial C}{\partial Y}\right|_{Y=0}
$$

while the friction factor is

$$
f . \operatorname{Re}=2\left(\frac{\partial U}{\partial Y}\right)_{Y=0}
$$




\section{Numerical Method}

The control volume method was used to solve the coupled PDEs (Eqs. 2-6) and the velocity-pressure coupling is treated by the SIMPLER algorithm (Patankar 1980). The grid is non-uniform in both the streamwise and transverse directions with greater node density near the inlet and the walls. The details of this grid independence test are provided in a previous work (Ait Hammou et al. 2004). A grid with 100 nodes in the axial direction and 35 nodes in the transverse one is adopted in this study. Convergence of the iterative procedure is declared when the relative variation of any dependent variable is less than $10^{-4}$ and the mass source residual falls below $10^{-6}$. The computer code was validated with the results available from the literature (Shah and London 1978) for thermal developing forced convection.

In addition, good agreement was found between our calculations and those from Yan and Lin (1989) for mixed convection heat and mass transfer. The details of these validations are presented elsewhere (Ait Hammou et al. 2004, Oulaid et al. 2010a and 2010b). An additional validation for the specific conditions considered here has been carried out. Fig. 2a shows the comparison between our results and Eq. (19) which gives the mean Nusselt number according to Stephan (Shah-London, 1978) for the simultaneous hydrodynamic and thermal development convection in a vertical parallel-plate channel with an isothermal and an insulated plate.

$$
N u_{m, T}=7.55+\frac{0.024\left(x^{*}\right)^{-1.14}}{1+0.00358\left(x^{*}\right)^{-0.64} \operatorname{Pr}^{o .17}}
$$

Moreover, our results were compared to those of Mercer (Shah and London 1978) given by Eq. (20).

(a)

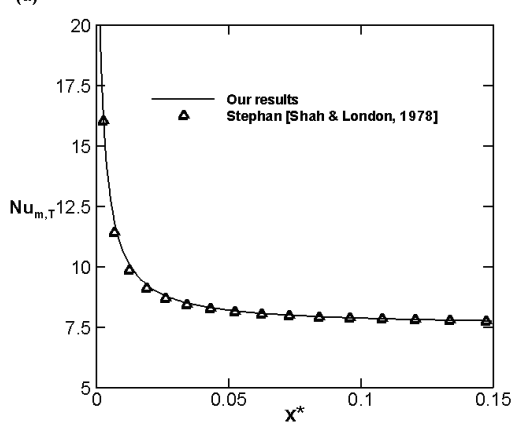

(b)

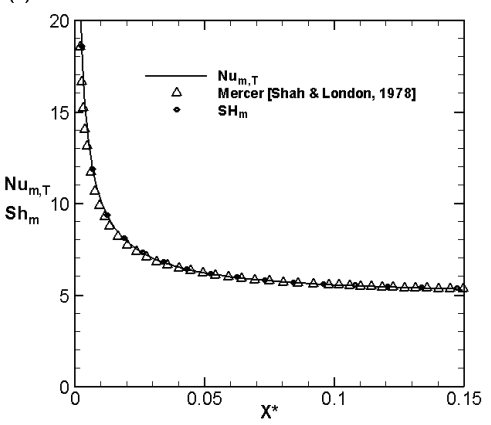

Fig. 2. Comparison between our results and those from the literature
Figure $2 \mathrm{~b}$ shows this comparison. The heat-mass transfer analogy was used to calculate the Sherwood number. Good agreements were found for these two comparisons.

$N u_{m, T}=4.86+\frac{0.32\left(x^{*}\right)^{-1.2}}{1+0.24\left(x^{*}\right)^{-0.7} \operatorname{Pr}^{0.17}}$

where $\mathrm{x}^{*}=\frac{X}{\mathrm{D}_{\mathrm{h}} \operatorname{Re} \operatorname{Pr}}$

\section{ReSUltS AND Discussion}

The results presented in the first part of this section were calculated with an aspect ration $\gamma=1 / 50, \mathrm{Re}=300$, $\mathrm{T}_{\mathrm{w}}=20^{\circ} \mathrm{C} \mathrm{T}_{\mathrm{in}}=40^{\circ} \mathrm{C}$ and $\phi_{\text {in }}=45.5 \%$. Therefore $\omega_{\text {in }}=$ $20.9 \mathrm{~g} / \mathrm{kg}$. Note that the mass fraction at the walls $\omega_{\mathrm{w}}$ is calculated assuming saturation conditions at $\mathrm{T}_{\mathrm{w}}$ and treating air-vapor mixture as an ideal gas mixture (Eq. 12). Thus, $\omega_{\mathrm{w}}=14.7 \mathrm{~g} / \mathrm{kg}$. Thermo-physical properties are taken to be constant and evaluated at a reference temperature and concentration given by the one-third rule $\left(\mathrm{T}_{\mathrm{ref}}=\left(\mathrm{T}_{\mathrm{in}}+2 \mathrm{~T}_{\mathrm{w}}\right) / 3\right.$ and $\left.\omega_{\mathrm{ref}}=\left(\omega_{\mathrm{in}}+2 \omega_{\mathrm{w}}\right) / 3\right)$ (Chow and Chung 1983). These authors have shown that this rule works well even at high temperatures when the stream is mostly air. This condition is prevalent in the present computations as $\omega$ is weak. The properties of air, water and their mixture are evaluated by formulas given by Fuji et al. (1977). So, $\operatorname{Pr}=0.71$, $\mathrm{Sc}=0.56, \mathrm{Gr}_{\mathrm{T}}=-1.6410^{5}$ and $\mathrm{Gr}_{\mathrm{M}}=-10^{4}$. Note that $\mathrm{Gr}_{\mathrm{T}}$ and $\mathrm{Gr}_{\mathrm{M}}$ are negative, thus the buoyancy forces act in the opposite direction of the upward flow. The buoyancy ratio $\mathrm{N}\left(=\mathrm{Gr}_{\mathrm{M}} / \mathrm{Gr}_{\mathrm{T}}=0.061\right)$ is weak, thus the thermal buoyancy force is dominant here. Four different inclination angles were considered, $\varphi=0^{\circ}$ (horizontal channel), $30^{\circ}, 60^{\circ}$ and $90^{\circ}$ (vertical channel). In the second part, we varied the Reynolds number to determine the conditions under which flow reversal occurs.

\subsection{Friction Factor}

The axial evolution of the friction factor, $f$ at the lower wet plate $(\mathrm{Y}=0)$ is shown in Fig. 3a. We note that this evolution is not monotonous for all the inclination angles while it is for the forced convection case. In the latter case $f$ tends towards the asymptotic value $f$. $\operatorname{Re}_{\infty}=$ 24 which is the analytical value for a fully developed flow (Shah-London, 1978). For an inclined channel, the buoyancy forces have an axial component which decelerates the fluid near the lower plate and consequently decreases $f$. This decrease becomes more significant for large values of the inclination angle. Table 1 presents the values of the minimum of $f$.Re and the corresponding axial positions. We notice that this minimum is negative for $\varphi=60^{\circ}$ and $90^{\circ}$. Examination of Fig. 3a shows that $f$.Re takes negative values over some part of the channel: $0.9 \leq X \leq 6.14$ for $\varphi=90^{\circ}$ and $1.05 \leq X \leq 5.04$ for $\varphi=60^{\circ}$. In those portions, the axial velocity $U$ is negative, which indicates flow reversal. This is caused by the axial component of the buoyancy forces, which are opposed to the upward flow. To show the effect of the transverse component of buoyancy forces on the friction factor, it is presented on 
Table 1. Minimum values of the friction factor near the lower wet plate

\begin{tabular}{cccccc}
\hline$\varphi$ & $0^{\circ}$ & $30^{\circ}$ & $45^{\circ}$ & $60^{\circ}$ & $90^{\circ}$ \\
\hline $\mathrm{X}$ & 4.05 & 2.54 & 2.43 & 2.37 & 2.44 \\
\hline$f . \mathrm{Re}_{\min }$ & 22.69 & 6.77 & 0.11 & -4.86 & -8.46 \\
\hline
\end{tabular}

Fig. $3 \mathrm{~b}$ for both the upper and lower plates. This figure shows that this component has a significant effect on $f$. One notes that, the flow is accelerated near the upper plate while it is decelerated near the lower one.

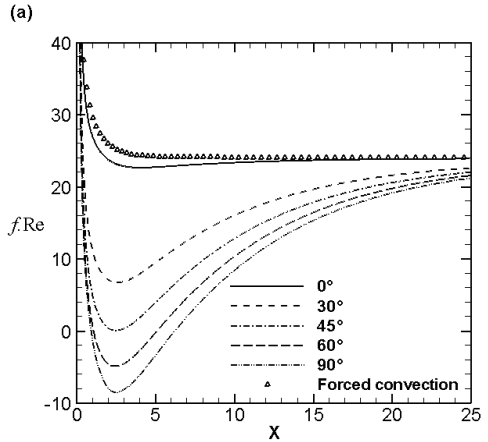

(b)

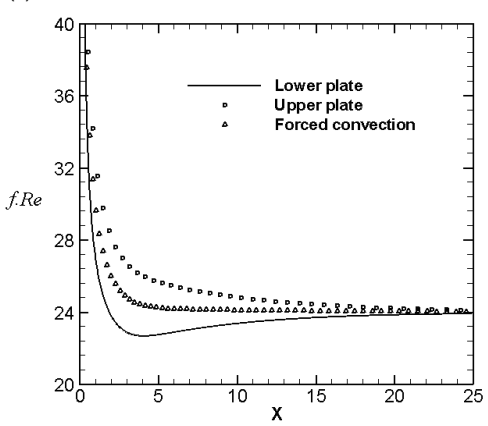

Fig. 3. Axial evolution of the friction factor, (a) Inclination effect at the lower wet plate, (b) Comparison between the upper and lower plates for horizontal channel

\subsection{Axial Velocity Profiles}

Figure 4 illustrates the effect of the buoyancy forces on the axial velocity profile at the axial position $(X=2.44)$ corresponding to the minimum of the friction factor for a vertical channel $\left(\varphi=90^{\circ}\right)$. The case of forced convection is also reported for comparison. It is obvious that buoyancy forces produce a significant deformation of the axial velocity profile. This distortion results in a deceleration near the walls and acceleration on the axis of the channel. This distortion is due to the axial component of the buoyancy forces. Here the fluid is more decelerated near the lower wet plate than near the upper dry one because the mass buoyancy force is weak close to the latter. Regarding the horizontal case, the $\mathrm{U}$ profile is slightly distorted due to the transverse component of the buoyancy forces.

Figure 5 show the velocity profiles for different inclination angles. These figures confirm the above observations and show that the velocity profiles tend faster to the parabolic profile for small inclination angles.

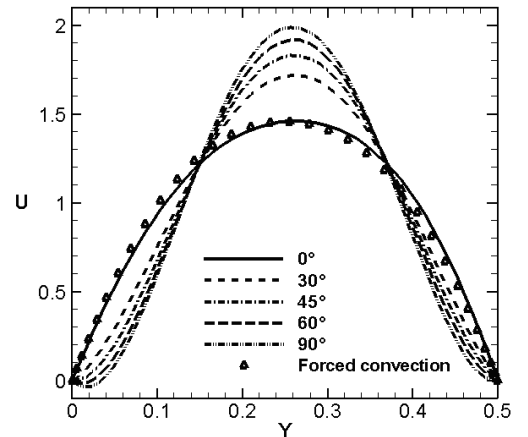

Fig. 4. Axial velocity profiles at $X=2.44$
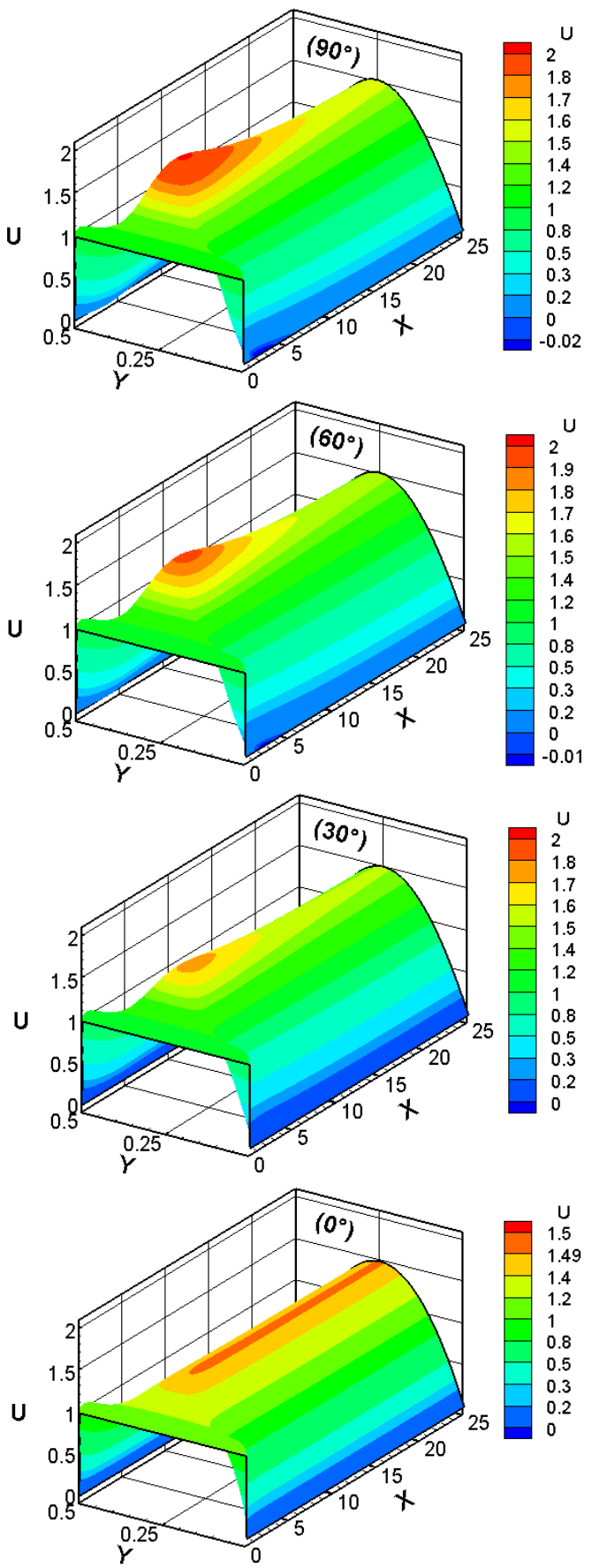

Fig. 5. Axial velocity profiles 

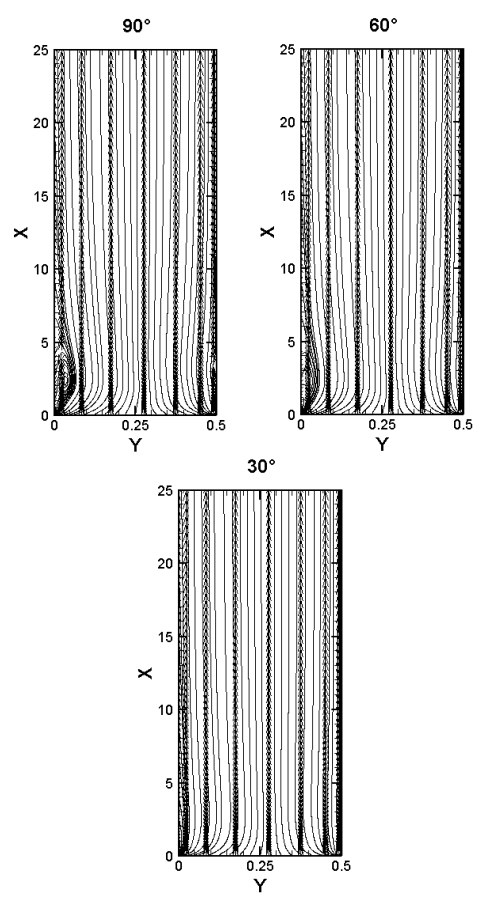

Fig. 6. Streamlines for different inclination angles

\subsection{Streamline}

Figure 6 shows the streamlines for different channel inclinations. At the channel entrance, these streamlines are deflected away from the plates. This is caused by the transverse gradients of temperature and mass fraction, which are significant, in addition to the growth of the boundary layer. This effect is less notable near the channel axis where the transverse gradients are weak. As the flow develops through the channel, it undergoes a deceleration due to the opposing buoyancy forces. This deceleration results in recirculation cells with different sizes depending on the channel inclination. Remember that the channel is asymmetric, and thus the buoyancy forces near the lower wet plate are more significant than those near the upper dry one. The recirculation cells consist of closed streamline contours and some of the streamlines in the region with negative velocity are normal to the lower plate $(\mathrm{Y}=0)$ due to the transverse vapor velocity $\mathrm{V}_{\mathrm{e}}$ and the condensation phenomenon, which will be addressed in the following section.

\subsection{Transverse Vapor Velocity}

Figure 7 presents the axial evolution of the dimensionless transverse vapor velocity, $V_{e}$, at the lower wet plate for different inclinations. The case of forced convection is also presented. We note that $\mathrm{V}_{\mathrm{e}}$ is negative which indicate that water vapor is transferred from airflow towards the plate. Thus this situation corresponds to the condensation of the water vapor on the walls. At the channel entrance, the magnitude of $V_{e}$ takes relatively greater values due to the large mass fraction gradient in this region. It is interesting to note that close to the channel entrance, $(X<4.37)$ the magnitude of $\mathrm{V}_{\mathrm{e}}$ for forced convection (and the horizontal channel too) is larger than for inclined channel; while further downstream forced convection results in lower values of $V_{e}$ magnitude. As indicated by Eq. (11) this behaviour reflects the axial variation of the non-dimensional mass fraction gradient at the wall. This inversion in $V_{\mathrm{e}}$ tendency occurs at $X \cong 4.37$. This axial position is closer to the location of the friction factor minimum (Fig. 3) and is within the flow reversal zone. It is believed that flow reversal plays a role in the inversion of $\mathrm{V}_{\mathrm{e}}$ tendency (Oulaid et al. 2010a). Finally, as the air moves downstream, it is dehumidified and the mass fraction gradient becomes lower. Therefore, $\mathrm{V}_{\mathrm{e}}$ tends monotonically towards zero.

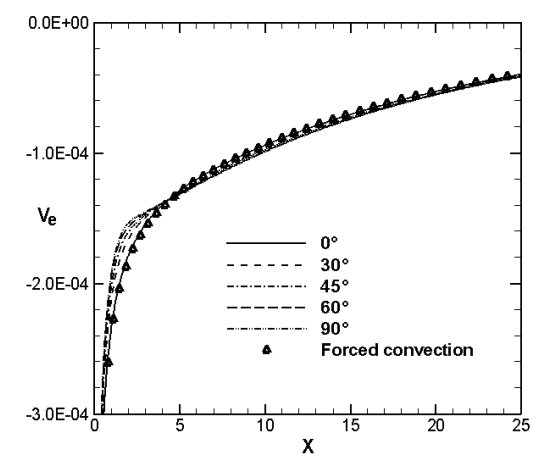

Fig. 7. Axial evolution of the dimensionless vapor velocity at the lower plate $\left(\mathrm{Y}=1.3310^{-4}\right)$

\subsection{Dimensionless Mass Fraction and Temperature Profiles}

Figure 8 illustrate the axial development of the dimensionless mass fraction and temperature profiles. By comparing these figures, the profiles of $\theta$ and $C$ develop in a similar manner (the fluid temperature and its vapour content decrease monotonically as $\mathrm{X}$ increases). We note that these profiles develop a bit faster in the case of forced convection and horizontal channel.

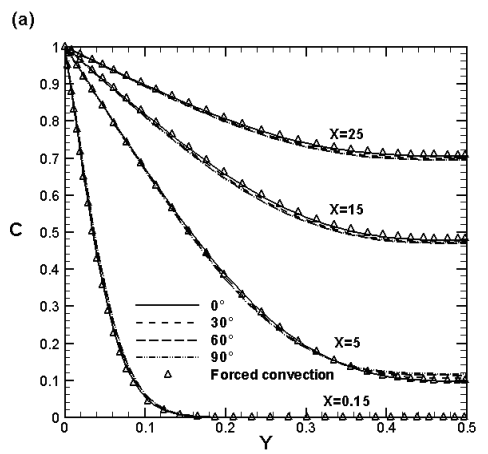

(b)

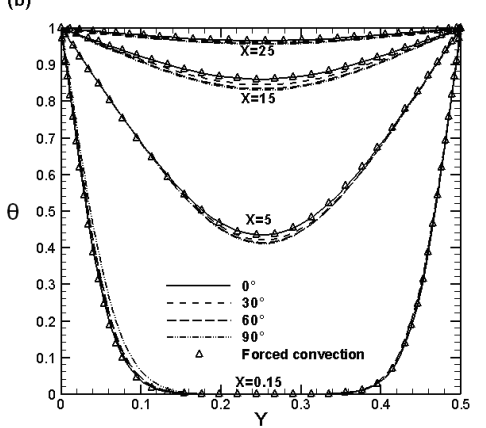

Fig. 8 Dimensionless profiles: (a) mass fraction, (b) temperature 
This simply results from the fact that in the present case heat and mass transfers decreases under the effect of the adverse buoyancy forces. Therefore, far from the entrance dimensionless temperature and mass fraction for mixed convection are lower than the corresponding values for forced convection. Accordingly, for the corresponding conditions, mixed convection results in higher mass fractions and temperatures far from the entrance.
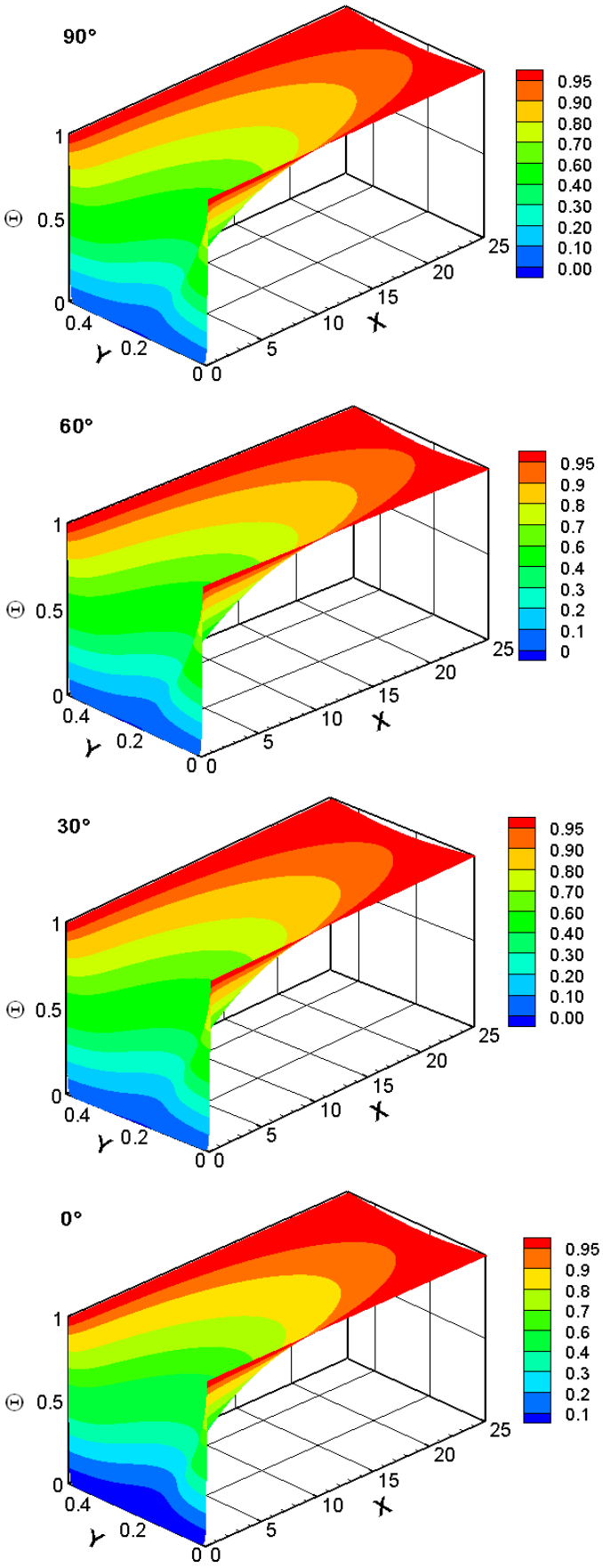

Fig. 9. Dimensionless temperature profiles

Figures 9 and 10 show the dimensionless temperature and mass fraction profiles for different channel inclinations. These figures confirm the above observation.
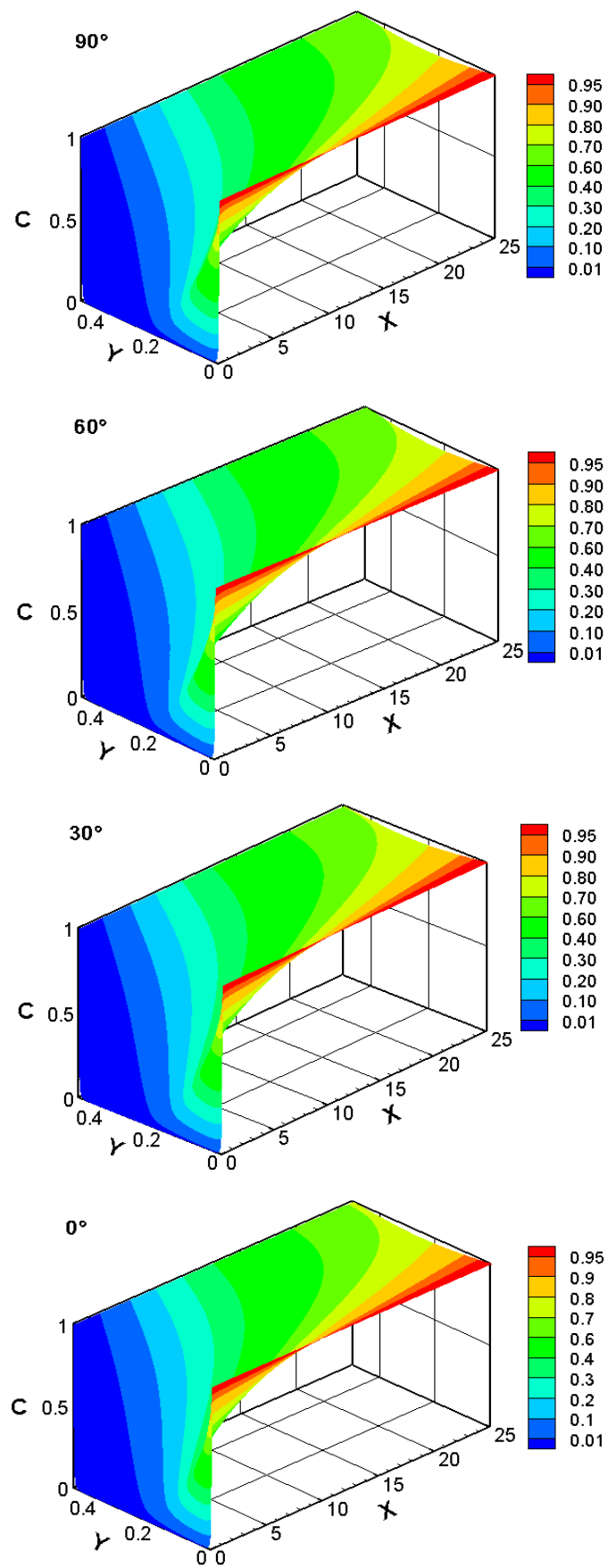

Fig. 10. Dimensionless mass fraction profiles

\subsection{Mean Dimensionless Temperature}

Figure 11 depicts the mean dimensionless temperature $\theta_{\mathrm{m}}$ profiles. It is noticed that the axial development of $\theta_{\mathrm{m}}$ is as low as the channel approaches the vertical position. Indeed, for a given axial position, $\theta_{\mathrm{m}}$ takes the lower value for $\varphi=90^{\circ}$ and the higher one for $\varphi=0^{\circ}$. This behavior is attributed to the action of the axial component of buoyancy forces. As stated in sections 4.1 and 4.2 this component acts in the opposite direction of the flow and its action results in a deceleration of the upward flow near the walls. Therefore, heat transfer between the airflow and the isothermal plates is reduced as the channel approaches its vertical position. 


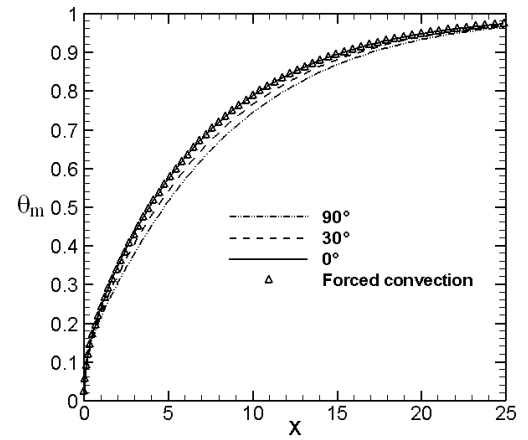

Fig. 11. Mean dimensionless temperature

\subsection{Sherwood Number}

Figure 12 presents the axial evolution of Sherwood number, Sh, which characterizes the mass transfer between the airflow and the lower wet plate. By analyzing this figure, the evolution of $\mathrm{Sh}$ is monotonous for all cases except for $\varphi=60^{\circ}$ and $\varphi=90^{\circ}$ where it exhibits a minimum. This minimum, as well as its axial location, depend on the channel inclination. This reduction of $\mathrm{Sh}$ is due to the axial buoyancy forces whose intensity increases with $\varphi$. These forces, acting downward, decelerate the upward flow, and thus decrease mass transfer. Towards the channel exit, Sh increases again and tends towards the same asymptotic value of 4.86, which corresponds to the fully developed flow with mass transfer between humid and impermeable plates (Shah-London, 1978).

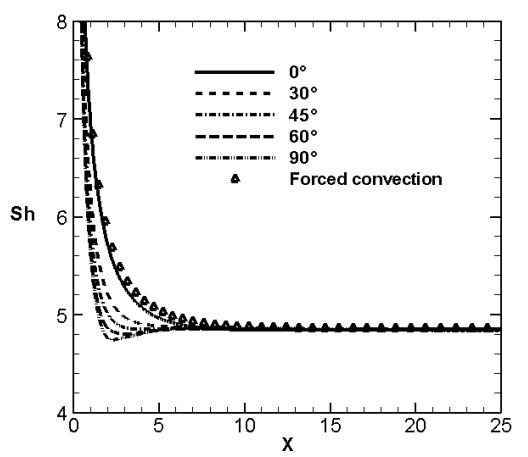

Fig. 12. Axial evolution of Sherwood number at the lower wet plate

\subsection{Sensible Nusselt Number}

The axial evolution of the sensible Nusselt number, $\mathrm{Nu}_{\mathrm{S}}$, at the lower plate is shown in Fig. 13a. Since the plates are maintained at a temperature lower than that of the entering airflow, the sensible heat transfer flux is always directed from the air towards the plates. Near the entrance $\mathrm{Nu}_{\mathrm{S}}$ takes large values due to the high temperature gradient. As the air moves downstream, it is cooled, thus $\mathrm{Nu}_{\mathrm{S}}$ decreases. This decrease is larger for the case of vertical channel for which the buoyancy forces have the highest axial component. In the case of forced convection the evolution of $\mathrm{Nu}_{\mathrm{S}}$ is monotonic. This is not the case for mixed convection. Indeed, $\mathrm{Nu}_{\mathrm{S}}$ has a minimum which depends on the channel inclination. Towards the channel exit, $\mathrm{Nu}_{\mathrm{S}}$ tends to the asymptotic value of 7.5 which corresponds to the fully developed forced convection flow. To bring out the effect of the transverse component of the buoyancy forces on $\mathrm{Nu}_{\mathrm{S}}$, the case of a horizontal channel $\left(\varphi=0^{\circ}\right)$ is considered. Fig. 13b presents a comparison of $\mathrm{Nu}_{\mathrm{S}}$ at the upper and lower plates. It is clear that, close to the channel entrance, $\mathrm{Nu}_{\mathrm{S}}$ is much higher for the upper plate than for the lower one. This is attributed to the buoyancy force action which slightly accelerates the flow in the vicinity of the upper plate (Figs. 4-5).
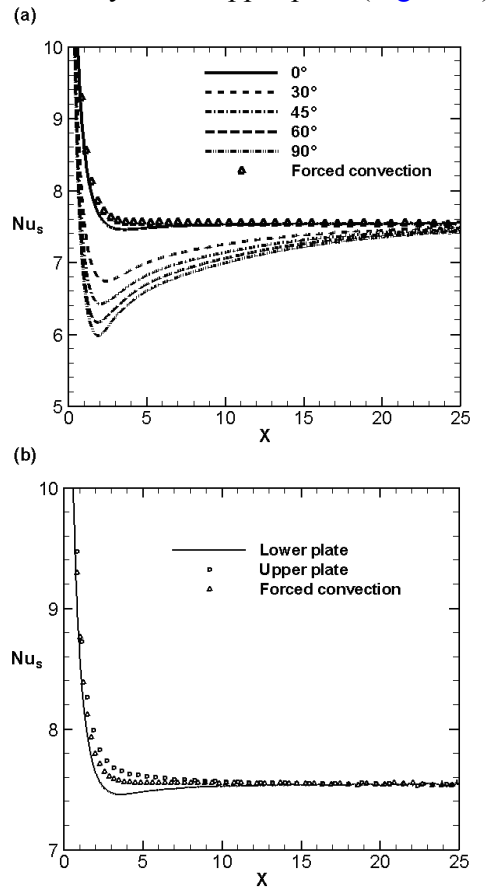

Fig. 13. Axial evolution of the sensible Nusselt number, (a) Inclination effect on $\mathrm{Nu}_{\mathrm{S}}$ at the lower plate, (b) Comparison between $\mathrm{Nu}_{\mathrm{S}}$ at the upper and lower plates for a horizontal channel

\subsection{Evolution of the Latent Nusselt Number}

Figure 14 presents the evolution of the latent Nusselt number $\left(\mathrm{Nu}_{\mathrm{L}}\right)$ along the channel for different inclinations. One notes that $\mathrm{Nu}_{\mathrm{L}}$ has the same sign as $\mathrm{Nu}_{\mathrm{S}}$, which means latent and sensible heat fluxes have the same direction, thus vapour contained in the air is condensed on the lower wet plate.

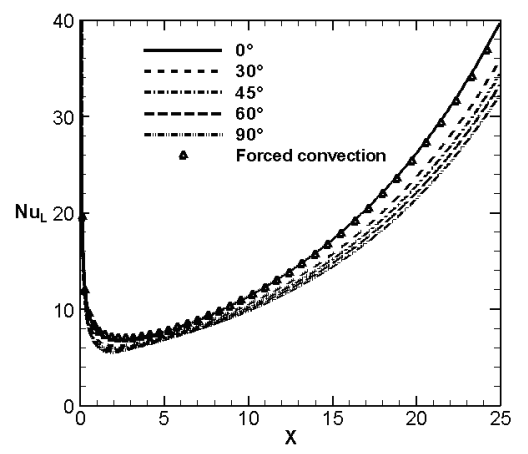

Fig. 14. Axial evolution of latent Nusselt number

$\mathrm{Nu}_{\mathrm{L}}$ takes large values very close to the channel entrance for all cases. This is explained by the strong gradients of mass fraction in the vicinity of the channel entrance. As the air moves downstream, water vapour is transferred from air to the lower plate (condensation), 
thus the gradient of mass fraction decreases, and that explains the decrease of $\mathrm{Nu}_{\mathrm{L}}$. At a particular axial position, which is within the flow reversal zone, $\mathrm{Nu}_{\mathrm{L}}$ takes a minimum and then strongly increases. This behaviour is attributed to the development of the mean airflow temperature (Fig. 11). Indeed, according to Eq. (15) the denominator of $\mathrm{Nu}_{\mathrm{L}}\left(1-\theta_{\mathrm{m}}\right)$ tends towards zero more rapidly than the mass fraction gradient $\left.\left(\frac{\partial C}{\partial Y}\right)_{Y=0}\right)$

\subsection{Flow Reversal Chart}

The flow reversal phenomenon reported above (Figs. 36) has specified conditions to occur. To determine accurately these conditions, a series of numerical experiments were performed. Thus, for a given inclination angle, $\mathrm{Gr}_{\mathrm{M}}$ and $\mathrm{Re}$, we varied $\mathrm{T}_{\text {in }}$ (i.e. $\mathrm{Gr}_{\mathrm{T}}$ ) until detecting a negative axial velocity. Several values of Re were considered. Results of these numerical experiments are presented on the flow reversal chart in Fig. 15 for three inclination angles $\left(\varphi=30^{\circ}, 60^{\circ}\right.$ and $90^{\circ}$ ). We note that, for a given inclination angle, flow reversal curves are quasi-linear. Moreover, as the inclination angle decreases, the magnitude of $\mathrm{Gr}_{\mathrm{T}}$ causing flow reversal increases. Indeed, this flow reversal is caused by the axial component of the buoyancy forces whose magnitude is proportional to the inclination angle (Eq. 3). In the case of a horizontal channel $\left(\varphi=0^{\circ}\right)$, flow reversal does not occur because the axial component of the buoyancy forces is zero.

The dependence of the flow reversal condition on $\mathrm{Gr}_{\mathrm{M}}$ has been studied. Due to the weakness of this dependence, it is not presented here.

The flow reversal chart in Fig. 15 can be expressed by the following correlations:

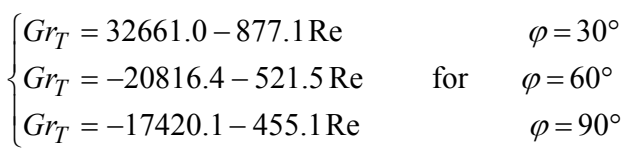

For $\mathrm{Gr}_{\mathrm{M}}=-10^{4}$ and any combination of the inclination angle and Reynolds number, these correlations give the value of $\mathrm{Gr}_{\mathrm{T}}$ which causes flow reversal.

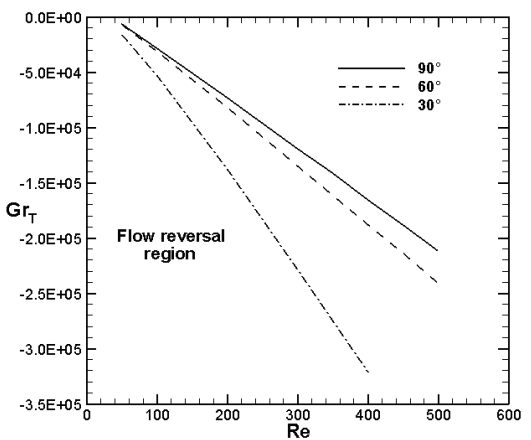

Fig. 15. Flow reversal chart for $\mathrm{Gr}_{\mathrm{M}}=-10^{4}$

\section{CONClusion}

Heat and mass transfer for mixed convection with phase change in an inclined parallel-plate channel, whose walls are isothermal and the lower one is wetted by a liquid water film while the upper plate is impermeable, was analyzed numerically. The effects of buoyancy forces and the channel inclination angle were specifically addressed. The results show that buoyancy forces decelerate the flow near the channel walls and induce flow reversal in the vicinity of the wet plate. Thus these forces reduce heat and mass transfer. The importance of this reduction depends strongly on the channel inclination angle. A chart of flow reversal has been established for different inclination angles. It specifies the values of Grashof numbers that induce flow reversal for a given Reynolds number and inclination angle.

\section{REFERENCES}

Ait Hammou, Z., B. Benhamou, N. Galanis and J. Orfi (2004). Laminar Mixed Convection of humid Air in a vertical channel with evaporation or condensation at the wall. International Journal of Thermal Sciences 43(6), 531-539.

Boussinesq, J. (1903). Théorie analytique de la chaleur. Gauthier-Villars, Paris, France.

Burmeister, L.C. (1993). Convective heat transfer. Wiley-Interscience, $2 \mathrm{~d}$ edition, New York, USA.

Chow, L.C. and J.N. Chung (1983). Evaporation of water into laminar stream of air and superheated steam. International Journal of Heat Mass Transfer 26(3), 373-380.

Fuji, T., Y. Kato and K. Bihara (1977). Expressions of transport and thermodynamic properties of air, steam and water. Sei San Ka Gaku Ken Kuu Jo, Report no 66, Kyu Shu University, Kyu Shu, Japan.

Gebhart, B. and L. Pera (1971). The nature of vertical natural convection flows resulting from the combined buoyancy effects of thermal and mass diffusion. International Journal of Heat Mass Transfer 14(12), 2025-2050.

Gray, D.D. and A. Giorgini (1976). The validity of the Boussinesq approximation for liquids and gases. International Journal of Heat Mass Transfer 19(5), 545-551.

Jang, J.H., W.M. Yan and C.C. Huang (2005). Mixed convection heat transfer enhancement through film evaporation in inclined square ducts. International Journal of Heat Mass Transfer 48(11), 2117-2125.

Laaroussi, N., G. Lauriat and G. Desrayaud (2009). Effects of variable density for film evaporation on laminar mixed convection in a vertical channel. International Journal of Heat Mass Transfer 52(12), 151-164.

Oulaid, O., B. Benhamou and N. Galanis (2010a). Combined buoyancy effects of thermal and mass diffusion on laminar forced convection in a vertical isothermal channel. Computational Thermal Sciences 2(2), 125-138. 
O. Oulaid et al. / JAFM, Vol. 5, No. 3, pp. 53-62, 2012.

Oulaid, O., B. Benhamou and N. Galanis (2010b). Flow reversal in combined laminar mixed convection heat and mass transfer with phase change in a vertical channel. International Journal of Heat and Fluid Flow, in press (doi:10.1016/j.ijheatfluidflow.2010.04.007).

Patankar, S.V. (1980). Numerical heat transfer in fluid flow. Hemisphere/McGraw-Hill, New York, USA.

Rheault, S. and E. Bilgen (1993). Mixed convection heat transfer in open-ended inclined channels with flow reversal. Wärme-und Stoffübertragung 29(2), 107-116.

Said, S.A.M., M.A. Habib, H.M. Badr and S. Anwar (2005). Turbulent natural convection between inclined isothermal plates. Computers and Fluids 34(9), 1025-1039.

Shah, R.K. and A.L. London (1978). Laminar flow forced convection in ducts. Academic Press, New York, USA.

Siow, E.C., S.J. Ormiston and H.M. Soliman (2007). Two-phase modelling of laminar film condensation from vapour-gas mixtures in declining parallel-plate channels. International Journal of Thermal Sciences 46, 458-466.

Yan, W.M. and T.F. Lin (1989). Effects of wetted wall on laminar mixed convection in a vertical channel. International Journal of Thermophysics and Heat Transfer 3, 94-96.

Yan, W.M. and C.Y. Soong (1993). Numerical study of liquid film cooling along an inclined plate. Wärme- und Stoffübertragung 28, 233-241.

Yan, W.M. and C.Y. Soong (1995). Convective heat and mass transfer along an inclined heated plate with film evaporation. International. Journal of Heat Mass Transfer 38, 1261-1269. 